\title{
Characteristics and main risk factors correlated to nausea and vomiting after painless digestive endoscopy
}

\section{Dan Wu}

Zhejiang Hospital

Cai-Fen Xi

Zhejiang Hospital

Ling Zhang

Zhejiang Hospital

\section{Peng Xu}

Zhejiang Hospital

\section{Zhi Chen ( 2564337747@qq.com )}

Tongde Hospital of Zhejiang Province

\section{Research Article}

Keywords: Digestive endoscopy, Nausea, Vomiting, Risk factors, Logistic regression analysis

Posted Date: November 9th, 2021

DOI: https://doi.org/10.21203/rs.3.rs-1013253/v1

License: (a) (i) This work is licensed under a Creative Commons Attribution 4.0 International License. Read Full License 


\section{Abstract \\ Background}

Nausea and vomiting is relatively frequent after painless digestive endoscopy. It not only occurs after surgery, but may also occur after painless digestive endoscopy. Here we study the characteristics and main risk factors associated with nausea and vomiting after painless digestive endoscopy.

\section{Methods}

A retrospective analysis of 1336 patients who had undergone painless digestive endoscopy in our hospital from January 2020 to May 2020 was performed. The incidence and timing of nausea and vomiting was examined, and the risk factors of nausea and vomiting of painless digestive endoscopy were analyzed.

\section{Results}

57 cases had nausea or vomiting (4.3\% of 1336 cases, female to male ratio $3.38: 1$, average age $49.49 \pm$ 13.30 years). 55 cases had nausea $(4.1 \%)$ and 39 cases had vomiting (2.9\%). Nausea and vomiting mostly occur within 6 hours after painless digestive endoscopy. In one-way analysis of variance, female, weight less than $60 \mathrm{~kg}$, diazoxide dose exceeding $2.5 \mathrm{mg}$, history of motion sickness, and history of smoke had significant correlation with nausea and vomiting, while female ( $O R=3.640, P=0.001)$, weight less than $60 \mathrm{~kg}(\mathrm{OR} 0.942, \mathrm{P}=0.001)$, diazoxide dose exceeding $2.5 \mathrm{mg}(\mathrm{OR}=2.074, \mathrm{P}=0.000)$ were independent risk factors of nausea and vomiting after painless digestive endoscopy by logistic regression analysis.

\section{Conclusions}

In our patients, female, weight less than $60 \mathrm{~kg}$ and the dosage of diazoxide more than $2.5 \mathrm{mg}$ are the main risk factors of nausea and vomiting after painless digestive endoscopy. This study suggests that the dose of diazoxide no more than $2.5 \mathrm{mg}$ may reduce the occurrence of nausea and vomiting after painless digestive endoscopy.

\section{Background}

Painless digestive endoscopy is one of the most commonly used methods for the diagnosis and treatment of digestive system diseases, usually performed under a certain degree of sedation and analgesia. Compared with ordinary painful digestive endoscopy, painless digestive endoscopy is more comfortable and has become the first choice for most patients in China. Although painless digestive endoscopy has many advantages, some complications cannot be completely avoided, such as nausea 
and vomiting. The incidence of nausea and vomiting after painless digestive endoscopy varies due to different patients and different anesthetic methods, fluctuating from 3.3-33.3\% [1, 2]. Once nausea or vomiting occurs, patients will have a bad experience. Mild nausea and vomiting will cause dehydration, fatigue, and electrolyte disturbance, while severe nausea and vomiting can cause psychological shadows in patients and lead to a prolonged hospital stay. Therefore, it is important to identify high-risk factors early and prevent nausea and vomiting for painless digestive endoscopy. There are many studies on postoperative nausea and vomiting, but few studies on nausea and vomiting after painless digestive endoscopy. Routine prevention and treatment of postoperative nausea and vomiting methods are not always suitable for special occasions [3], it is extremely necessary to develop a special nausea and vomiting prediction model for painless digestive endoscopy. This study retrospectively analyzed the clinical data of 1336 patients in China underwent painless digestive endoscopy and explored the high-risk factors for nausea and vomiting after painless digestive endoscopy, to provide a reference for reducing the incidence of nausea and vomiting after painless digestive endoscopy.

\section{Methods}

\section{Patients}

This article retrospectively analyzed data from 1336 patients underwent painless digestive endoscopy in Zhejiang hospital from January 2020 to May 2020. The study was approved by the Ethics Committee of Zhejiang Hospital and complies with the Declaration of Helsinki. All participants provided informed consent. Among them, there were 391 cases of painless gastroscopy, 383 cases of painless colonoscopy, and 562 cases of painless gastrointestinal endoscopy. The ASA classification of all patients were I III. The age of all patients ranged from 20 to 80 years old. Cases included 693 male patients and 643 female patients $₫$ male to female ratio 1.08: 1, average age $49.49 \pm 13.30$ years). Exclusion criteria:1. the patient's data was incomplete; 2 . the patient had severe gastrointestinal diseases such as gastroparesis, gastroesophageal reflux, pyloric obstruction, and intestinal obstruction.

\section{Method of treatment}

In our endoscopy center, all patients undergo painless digestive endoscopy with intravenous anesthesia. Patients received a single dose of dezocine $(0 \sim 5 \mathrm{mg})$ and propofol $\left(1.5 \sim 2.5 \mathrm{mg}^{\circ} \mathrm{kg}^{-1}\right)$ in anesthesia induction. If abnormalities happen during the endoscopy such as body movement or coughing, the patient was injected propofol $0.05 \sim 0.1 \mathrm{mg} \cdot \mathrm{kg}^{-1}$. Besides, Patients undergoing painless colonoscopy or gastrointestinal endoscopy were given intravenous injection of Nospar (40 mg). Patients undergoing painless gastroscopy or painless gastrointestinal endoscopy orally took $10 \mathrm{ml}$ lidocaine hydrochloride glue before the examination.

Postoperatively, medical staffs would follow up all patients by telephone to find out whether the patient had nausea, vomiting, or other discomfort within 2 days after the examination. According to the follow-up results, patients were divided into two groups. Nausea and vomiting group included patients who had 
nausea or vomiting within one day after the inspection. Non-nausea and vomiting group include patients neither had nausea nor vomiting. The incidence of nausea and vomiting was measured as the primary outcome.

\section{Data collection}

The patient's gender, age, weight, examination items, history of motion sickness, history of smoke, the conditions during the examination including dosage of diazoxide, the dosage of propofol, the use of Nospar, the use of lidocaine, and total time of examination (from the endoscope entering the patient's body to coming out) were collected.

\section{Statistics}

SPSS20.0 statistical software was used for statistical processing. The sample size of 1336 participants were based on a priori analysis ( $a=0.05 ; 11$ predictor variables). One-way analysis of variance was used to compare the incidence of nausea and vomiting and related factors between two groups. Variables considered statistically significant in the one-way analysis of variance were included in multivariate analysis, using Logistic Regression model (Forward: LR).

\section{Results}

57 patients had nausea or vomiting (4.3\%, female to male ratio 3.38:1, average age $49.49 \pm 13.30$ years, ) within one day after the inspection; 55 patients had nausea (4.2\%); 39 patients had vomiting (2.9\%). Nausea and vomiting mainly occurred within 4 to 6 hours after the painless digestive endoscopy, among them, 24 cases occurred within 0 to 2 hours after the inspection; 21 cases occurred within 3 to 4 hours; and 9 cases occurred within 5 to 6 hours. Only 3 cases occurred 10 to 12 hours after the inspection.

In one-way analysis of variance, there were significant differences in gender, weight, dosage of diazoxide, history of motion sickness, and history of smoke between nausea and vomiting group and non-nausea and vomiting group. Female, weight less than $60 \mathrm{~kg}$, diazoxide dose exceeding $2.5 \mathrm{mg}$, history of motion sickness, and history of smoke were risk factors predicting nausea and vomiting of painless gastrointestinal endoscopy. There are no significant differences in inspection items, dosage of propofol, the use of drotaverine hydrochloride, and the use of lidocaine glue, and total inspection time (Table 1).

In logistic regression analysis, we included risk factors which showed significant difference in one-way analysis of variance and found out that female $(O R=3.640, P=0.001)$, weight less than $60 \mathrm{~kg}(O R$ 0.942, $\mathrm{P}=0.001)$, diazoxide dose exceeding $2.5 \mathrm{mg}(\mathrm{OR}=2.074, \mathrm{P}=0.000)$ were independent risk factors of nausea and vomiting after painless digestive endoscopy (Table 2).

In this study, we found that 49 of 57 patients with nausea and vomiting (86.0\%) had more than $2.5 \mathrm{mg}$ of diazoxide, and 821 of 1279 patients without nausea and vomiting (64.2\%) had more than $2.5 \mathrm{mg}$ of diazoxide, with a statistically significant difference in diazoxide dosage between those with more than $2.5 \mathrm{mg}$ of diazoxide and those with no more than $2.5 \mathrm{mg}$ of diazoxide(OR=2.074, $\mathrm{P}=0.000)$. Logistic 
regression models, after adjusting for sex and weight, showed an increased risk of nausea and vomiting in those with more than $2.5 \mathrm{mg}$ of diazoxide relative to those with less than $2.5 \mathrm{mg}$ of diazoxide, as shown in Table 2.

Table1 One-way analysis of related factors of nausea and vomiting after painless digestive endoscopy 


\begin{tabular}{|c|c|c|c|c|}
\hline & $\begin{array}{l}\text { Nausea and vomiting } \\
\text { group } \rrbracket n=57 \rrbracket\end{array}$ & $\begin{array}{l}\text { Non-nausea and vomiting } \\
\text { group } \llbracket n=1279 \rrbracket\end{array}$ & $c^{2}$ & $P$ Value \\
\hline Age (years) & & & 0.362 & 0.547 \\
\hline$<60$ & 45 & 965 & & \\
\hline$\geq 60$ & 12 & 314 & & \\
\hline Gender & & & 20.146 & 0.000 \\
\hline Male & 13 & 680 & & \\
\hline Female & 44 & 599 & & \\
\hline Weight(kg) & & & 22.128 & 0.000 \\
\hline$<60$ & 38 & 459 & & \\
\hline$\geq 60$ & 19 & 820 & & \\
\hline Examination item & & & 0.751 & 0.687 \\
\hline Painless gastroscope & 19 & 372 & & \\
\hline Painless colonoscopy & 17 & 366 & & \\
\hline $\begin{array}{l}\text { Painless } \\
\text { gastrointestinal } \\
\text { endoscopy }\end{array}$ & 21 & 541 & & \\
\hline $\begin{array}{l}\text { History of motion } \\
\text { sickness }\end{array}$ & & & 7.978 & 0.005 \\
\hline No & 38 & 1042 & & \\
\hline Yes & 19 & 234 & & \\
\hline History of smoke & & & 6.173 & 0.013 \\
\hline No & 51 & 959 & & \\
\hline Yes & 6 & 319 & & \\
\hline Dosage of diazoxide & & & 11.390 & 0.001 \\
\hline$<2.5 \mathrm{mg}$ & 8 & 458 & & \\
\hline$\geq 2.5 \mathrm{mg}$ & 49 & 821 & & \\
\hline Dosage of propofol & & & 0.006 & 0.937 \\
\hline$<180 \mathrm{mg}$ & 27 & 599 & & \\
\hline$\geq 180 \mathrm{mg}$ & 30 & 680 & & \\
\hline $\begin{array}{l}\text { Use of drotaverine } \\
\text { hydrochloride }\end{array}$ & & & 1.354 & 0.245 \\
\hline
\end{tabular}




\begin{tabular}{|lllll|}
\hline no & 22 & 400 & & \\
\hline yes & 35 & 879 & 0.441 & 0.507 \\
\hline Use of lidocaine glue & & & & \\
\hline No & 14 & 366 & & \\
\hline Yes & 43 & 913 & 0.222 & 0.638 \\
\hline Total inspection time & & & & \\
\hline$<15$ min & 29 & 610 & & \\
\hline$\geq 15$ min & 28 & 669 & & \\
\hline
\end{tabular}

Table 2 Logistic regression analysis of risk factors of nausea and vomiting after painless gastrointestinal endoscopy

\begin{tabular}{|c|c|c|}
\hline Risk factor & OR $₫ 95 \% \mathrm{Cl} \rrbracket$ & $P$ \\
\hline \multicolumn{3}{|l|}{ Weight } \\
\hline$\geq 60 \mathrm{~kg}$ & 1.000 & \\
\hline$<60 \mathrm{~kg}$ & 0.942ه0.909 0.976\ & 0.001 \\
\hline \multicolumn{3}{|l|}{ Gender } \\
\hline male & 1.000 & \\
\hline female & 3.640ه1.655 8.009ه & 0.001 \\
\hline \multicolumn{3}{|l|}{ Diazoxide } \\
\hline$<2.5 \mathrm{mg}$ & 1.000 & \\
\hline$\geq 2.5 \mathrm{mg}$ & $2.074 \rrbracket 1.596 \sim 2.695 \rrbracket$ & 0.000 \\
\hline
\end{tabular}

\section{Discussion}

The benefits of comfort and painlessness of painless digestive endoscopy is favored by more and more patients. Compared with general anesthesia with tracheal intubation, the anesthesia for painless gastrointestinal endoscopy is relatively simpler, easier to operate, but the quality of anesthesia recovery for painless gastroscopy is not always ideal because of the fast pace, the huge rising numbers and the relative shortage of anesthesiologists in China. Patients may experience nausea and vomiting and other 
complications after the examination which decreases patients' satisfaction. So, how to improve this condition is our study's aim.

In this study, we found that the incidence of nausea or vomiting after the painless digestive endoscopy is $4.3 \%$. Among them, $4.2 \%$ patients had nausea with or without vomiting and $2.9 \%$ patients had vomiting with or without nausea. The incidence of nausea or vomiting in our study is relatively lower than other similarly endoscopic studies $[4,5]$. It is obviously that the incidence of nausea is higher than the incidence of vomiting after this painless inspection. The difference incidence may be caused by different mechanisms of nausea and vomiting and vomiting often causing more harm to patients than nausea.

We also found nausea and vomiting after painless digestive endoscopy mostly occurred early after the examination within $4 \sim 6 \mathrm{~h}$, and rarely more than $12 \mathrm{~h}$ after the examination. The incidence of nausea and vomiting is highest within 2 hours after the examination (42.1\%).

There are many influencing factors, such as patient factors (age, gender, history of motion sickness, smoking history, and individual differences), anesthetic factors (anesthetic modality and drugs), and surgical factors (surgical site, modality, and time) [6]. For general anesthesia with tracheal intubation, women, history of previous chemotherapy, and higher education are important risk factors for postoperative nausea and vomiting [7]. Similarly, this study found that female is one of the independent risk factors of nausea and vomiting after painless digestive endoscopy, with the risk of nausea and vomiting approaching 3 times than that of male. The mechanisms may be related to hormones and emotions [8]. Another study also show that women are more prone to nausea and vomiting after laparoscopic cholecystectomy under general anesthesia relative to men, and the risk of nausea and vomiting is approximately 2 3 times higher in women than in men [9]. Other risk factors such as history of motion sickness and history of smoking which may be correlated with nausea and vomiting did not play a significant role in our study.

In the present study, remarkably, there was a strong association of diazoxide dose over $2.5 \mathrm{mg}$ with painless gastroenteroscopic nausea and vomiting $(\mathrm{OR}=2.074)$. Even though diazoxide with propofol is safe and effective for painless colonoscopy with low respiratory depression and better analgesic effect [10], diazoxide has some side effect. One of the common side effects is nausea and vomiting. Opioids cause the occurrence of nausea and vomiting through multiple pathways including central and peripheral effects [11]. Increasing the dose of opioids leads to an increased risk of postoperative nausea and dizziness. But it's not as if the lower the dose of diazoxide, the better. It was showed that there was no statistical difference in the incidence of nausea and vomiting after the examination between small doses of diazoxide $(20 \mathrm{ug} / \mathrm{kg}$ ) combined with propofol for painless gastroscopy compared with propofol alone [12]. In future studies, the effects of propofol compounded with different doses of diazoxide or opioidsparing analgesics on the incidence of nausea and vomiting after the painless digestive endoscopy worth to be investigated.

In this study, weight $<60 \mathrm{~kg}$ was found to be one of the independent risk factors for nausea and vomiting in painless gastroenterology. Due to the mean weight of all patients in this study was $63.05 \pm 11.29$ years, 
we take $60 \mathrm{~kg}$ as the basis for classification in this study, which showed that the risk of nausea and vomiting was 0.381 times higher in patients weight $<60 \mathrm{~kg}$ than in those weight $\geq 60 \mathrm{~kg}$. The reason for this is presumed to be the fact that low body weight may increase the difficulty of colonoscopy and the lighter weight is generally associated with female patients who are prone to have nausea vomiting. This was in accordance with the results of Poon's study [13] which showed body weight (OR 0.98) was one of the independent predictors for postoperative vomiting under trauma surgery and the risk of postoperative vomiting decreases when body weight increases.

In conclusion, female, weight less than $60 \mathrm{~kg}$, diazoxide dose exceeding $2.5 \mathrm{mg}$ are the main risk factors of painless digestive endoscopy. To reduce the incidence of nausea and vomiting after painless digestive endoscopy, this study suggests using no more than $2.5 \mathrm{mg}$ of diazoxide when performing painless gastrointestinal endoscopy especially for female patients weighing less than $60 \mathrm{~kg}$.

\section{Abbreviations}

ASA: American Society of Anesthesiologists

BMI: body mass index

\section{Declarations}

- Ethics approval and informed consent to participate

The study was performed in accordance with the Declaration of Helsinki and relevant guidelines and regulations.

The study was approved by the Ethics Committee of Zhejiang Hospital.

All participants provided informed consent.

- Consent for publication

Not applicable

- Availability of data and materials

All data generated or analyzed during this study are included in this published article [and its supplementary information files].

- Competing interests

The authors declare that they have no competing interests

- Funding 
Non-funding

- Authors' contributions

WD: mainly collects data and writes articles

CZ: analyze data and assist with writing articles

XCF: provides research content and analyzes the latest literature reports

ZL: assists in collecting data and excluding inappropriate cases

$\mathrm{XP} \llbracket$ assists in follow-up of patients

All authors read and approved the final manuscript.

- Acknowledgements

Thanks to all anesthesiologists, endoscopists and nurses for their help. Thanks to all patients who cooperated with the follow-up survey.

- Authors' information (optional)

\section{References}

1. Zhe DENG, Zhemin LI, Jialing MO, et al. Efficacy of Etomidate combined with Dezocine for colonoscopy of elderly patients. China Medical Herald,2014;11(26):74-77

2. Hui Zheng. Anesthesia effect and safety of dezocine or fentanyl combined with propofol in endoscopic colon polyps resection. China Medicine. 2017, 12(9):1382-1385

3. Öbrink E, Jildenstål P, Oddby E, et al. Post-operative nausea and vomiting: update on predicting the probability and ways to minimize its occurrence, with focus on ambulatory surgery. Int J Surg. 2015,15:100-106.

4. Moheimani H, Yaseri M. Dexamethasone Reduces Postoperative Nausea in Pediatric Upper Endoscopy With Deep Sedation: A Randomized Controlled Trial. J Pediatr Gastroenterol Nutr. 2019 Sep;69(3):281-286. doi: 10.1097/MPG.0000000000002398. PMID: 31124887.

5. Seleem WM, El Hossieny KM, Abd-Elsalam S. Evaluation of Different Sedatives for Colonoscopy. Curr Drug Saf. 2020;15(1):20-24. doi: 10.2174/1574886314666190726154238. PMID: 31362661.

6. Veiga-Gil L, Pueyo J, Lopez-Olaondo L. Postoperative nausea and vomiting: physiopathology, risk factors, prophylaxis and treatment[J]. Revista espanola de anestesiologia y reanimacion 2017, 64(4):223-232.

7. Tao QIN, Yang LI, Xianlong XIE. Correlative Factor Analysis of Postoperative Nausra and Vomiting Related to General Anesthesia. Herald of Medicine. 2019, 38(11):1442-1445 
8. Yan Chang, Ya Cao, Zeping Dai, et al. Risk factors associated with postoperative nausea and vomiting in patients following thyroid surgery. J of Wannan Medical College.2017, 36(5):490-493. doi:CNKI:SUN:WNYX.0.2017-05-025.

9. Zhao Peng, Xuejun Kuang, Song He, et al. Logistic regression analysis of factors correlated to postoperative nausea and vomiting of laparoscopic cholecystectomy Journal of Xiangnan University (Medical Sciences). 2014, (4):19-22.

10. Senlin Li, Bingxin Xu, Yang Gao, et al. Clinical observation of dezocine plus propofol in painless colonoscopy for elderly patients. Journal of North Pharmacy. 2019, 16(05):8-10.

11. Yingcun Cai, Jinwei Xie, Jun Ma, et al. Risk factors of postoperative nausea and vomiting following primary total hip or knee arthroplasty under general anesthesia:a retrospective study. Chinese Journal of Bone and Joint Surgery. 2016,9(1):35-39

12. Ma J, Zhang P, Zhang Y, et al. Effect of dezocine combined with propofol on painless gastroscopy in patients with suspect gastric carcinoma. J Cancer Res Ther. 2016;12(Supplement):C271-C273.

13. Poon YY, Ke TY, Hung KC, et al. Risk Factors of Postoperative Vomiting in the Eye of "Real-World Evidence"-Modifiable and Clinical Setting-Dependent Risk Factors in Surgical Trauma Patients. J Pers Med. 2021 May 8;11(5):386. doi: 10.3390/jpm11050386. 